counties, has the highest death-rate. This is the reverse of what obtains in the geographical distribution of cancer and heart-disease.

2. The south-eastern counties, which have a high mortality, are characterised by elevated chalk-ranges, and valleys in which the oolitic, the cretaceous, and wealden clays predominate.

3. The eastern counties, having a high mortality, are exposed in aspect to the easterly'winds ; and the lower lands are characterised by clays of the Eocene period, especially the London clay.

5. We therefore see that high, dry, chalky sites, exposed to the free access of the east winds, are accompanied by a high death-rate from phthisis; and that the same death-rate obtains in the cold, damp, clayey valleys, which these chalk-ranges shelter.

I shall now proceed to the next series of county groups-those of low mortality.

In the distribution of heart-disease, we found a high mortality coincident with sheltered site; and again, in cancer, it was shown that the riparial districts of rivers, which ran through protected valleys, and seasonally flooded the adjoining counties, had a high mortality. These localities were well defined in both maps; and the counties that contained them were coloured with the blue characteristic of the proportional high mortality. For instance, the well sheltered counties of Hereford and Worcester, the one characterised by its fertile warm old Devonian formation, and the other by its not less fertile new red marl, had a high mortality, which was coincident with these counties being surrounded on all sides by lofty ranges, excluding the direct influence of the sea-winds. In the phthisis-map, we see these counties coloured so as to represent almost the lowest degree of mortality, and, with Warwickshire and Radnor, forming an oblong group, bisected by the Severn vale. Coincident with this low mortality is a sheltered site, lying on the warm and highly ferruginous red sandstone. Wiltshire, again, and Berkshire, are seen in the heart-disease map as high mortality counties; and we found within them that the districts most protected had the highest death-rate. These counties are coloured red in the phthisis-map. Devonshire, with its deep and fertile valleys and frequently flooded rivers, had a high mortality from both cancer and heart-disease. In phthisis, we find this county standing out conspicuously from its low mortality; and it is accompanied by Somersetshire, which, as I have before remarked, has no low mortality districts in the heart-disease, except where there is free access to the prevailing winds up the rivers Parrett and Avon.

Lincolnshire has a low mortality from phthisis, and forms an exception to the general rule, which at present seems hidden in obscurity. We must, however, remember that ague is prevalent in this part of England; and it has been said that this disease is seldom associated with consumption. A more significant coincident fact is the one that the greater portion of this land has been reclaimed from the sea. It is well known that many sites, although damp with sea-water, enjoy a remarkably low mortality from phthisis. That part of the North Riding of Yorkshire which we have seen to be protected by the oolitic range which forms its sea-boundary, and is traversed by the valleys of the Rye and Derwent, has an exceedingly low mortality; and so has the group to the north of Northumberland, both of which areas are coloured blue in the heart-disease map.

The remarkably low mortality of the two counties Middlesex and Surrey, which lie in the basin of the Thames, is another contrast to what obtains both in heart-disease and cancer. Middlesex we know to be chiefly composed of London clay; and a greater portion of Surrey belongs to the same formation. One county is protected by the northern boundary, and the other by the southern, of the Thames valley.

Recapitulation.-I. All the counties having the fifth or nearly the lowest death-rate from phthisis have been previously shown, in my last two lectures, to possess well sheltered areas, which in cancer and heart-disease were characterised by a high mortality.

2. Coincident with low mortality from phthisis in the counties to the west of $1^{\circ} \mathrm{W}$. longitude, were sites having a formation consisting of either old or new red sandstone.

3. Lincolnshire forms an exception to the rule of exposed sites being coincident with high mortality from phthisis. The prevalence of ague has been said to account for some decrease in the mortality, but the fact that the sites have been reclaimed from the sea is more worthy of attention.

4. The protected counties of the North Riding and Northumberland have a low mortality from consumption, and the reverse from heartdisease.

I shall now proceed to examine the districts, and endeavour to show how they carry out the facts that have been noticed in the divisions and counties.

$$
\text { [To be continued.] }
$$

\section{NOTES OF A LECTURE ON HAY-FEVER.*}

By E. SYMES THOMPSON, M.D., F.R.C.P., Gresham Professor of Medicine, and Physician to the Hospital for Consumption, Brompton.

THERE are persons of both sexes who are subject to violent sneezing and all the miseries of "cold in the head" during relaxing weather, when shut up in close rooms or heated theatres, who assert that they have "hay-fever", and declare, moreover, that hay-fever has nothing whatever to do with hay. There is also a form of "transient catarrh" which comes on for an hour or more every morning, which is very annoying to those who suffer from it, sometimes falsely called by this name. Hay-fever or "grass-asthma" is, however, quite distinct from these affections, and ai ises from a peculiar and unexplained idiosyncrasy, like that which makes some persons afraid of mushrooms or tomatoes, mercury or opium. Most of us have met with strange cases of this kind. I know an instance in which honey acts like a poison; another in which strawberries produce serious symptoms; and a third in which mutton in any form cannot be taken, though the patient is in no other respect a dyspeptic.

The effect of the inhalation of powdered ipecacuanha upon the nasopulmonary mucous membrane of some persons is analogous to that of the pollen of grasses upon others. The case is recorded of a chemist's apprentice so sensitive to this drug, that he was often seized with sneezing when at the top of the house whilst the ipecacuanha-root was being powdered at the bottom.

Of the various grasses which have the power of exciting the disease, the sweet-scented vernal grass (Anthoxanthum odoratum) is the most common. Certain varieties of Holcus, Alopecurus, Nardex, etc., seem to possess a similar irritant quality. All these are found to contain benzoic acid; and the presence of this acid has been regarded as the source of the evil. But in these days, when so much is said about "germs", the idea that minute particles are the source will be more readily received. If the sensations of the sufferers may be taken as a guide, it appears certainly as if there were sharp particles sticking in the throat, eyes, and nose ; and the sneezing, coughing, defluxion, and bronchial spasm, seem to be Nature's effort to remove the evil. Some are more sensitive to the influence of one kind of grass than of another. The grasses that ripen early are, as a rule, more irritating than those that flower late in the season. The second crop of hay has rarely any effect ; this may be partly due to the fact that it is usually mown before the flowers ripen. The irritant grasses are found to grow upon rich soils. As the poorer soils become more rich from cultivation, these grasses become more wide-spread, and thus the resulting malady becomes more general also. In the vicinity of the Bristol Channel, the grasses seem to be especially virulent; less so in the eastern parts of England; and in Ireland hay-fever is seldom heard of.

The increased frequency of the malady may be accounted for in another way. The present age being one of over-strain of the nervous system, disorders having relation to morbid excitability of nerve are in the ascendant; just as affections of the vascular and digestive organs, gout, apoplexy, etc., consequent on over-indulgence in the pleasures of the table, were usual in the days of our grandfathers.

Instead of enumerating the parts affected in this disease, and givinga general description of the symptoms, three cases will be described, illustrative of three forms of the disorder. The living pictures thus drawn will, it is thought, give a better notion of its main characters than a systematic account of the disorder. Thus, too, an opportunity is given of introducing, in the words of the patients themselves, some of those casual yet not unimportant minutiæ as to cause, character, and spread of the disease, which are not of a sufficiently positive nature to be laid down with authority. Herr Phœbus, in his work on Spring Catarrh, mentions that, of fifty-eight well marked cases, symptoms referable to the nose were present in all; to the eyes, in forty-eight; to the mouth and throat, in twenty-nine; head, in twenty-six ; chest, forty-five; whilst forty-three suffered also from general constitutional symptoms.

CASE I. - " The first time I distinctly remember an attack of hay-fever was in June 1850 , when about ten years old. I was playing in a hayfield, and thought that I had suddenly caught a violent cold. But this supposed cold vanished on going to London next day. Although much the same thing happened in one or two successive years, it was never acknowledged that I had hay-fever till 1859 , in which year, as in 1860 , the attack was especially severe. From that time till 1864, when the dangerous weeks of June were spent at the seaside, the attack recurred annually, in various degrees of discomfort. London seems the safest air during the hay-season. The glare of the streets brings on 
sneezing, but not the intense irritation of throat, ears, and palate, which is with me, I believe, indicative of the actual presence of the vernal grass. I feel first a sensation of heat and fulness in the eyes, passing along the lids and over the eyeball ; slight redness; and discharge of tears. This state gradually increases till acute itching and smarting occurs, with the sensation of small points sticking upon and darting into the eyeball. The eyes become extremely inflamed, and discharge a thick fluid. As the day advances, the symptom increase, and the conjunctiva becomes quite odematous, relief being alone gained by rest in a dark room. Such, too, is the irritation of the throat and palate, that I try to scratch the latter with the tip of my tongue; and on bad days I feel as if this region had been sprinkled with Cayenne pepper. There is a sense of fulness after sneezing, and of derangement about the back of the throat and palate, accompanied by a most trying itching in the Eustachian tube, which induces a desire to move the back of the tongue and thrust the fingers into the ears; but, as the part affected cannot be reached, the itching can scarcely ever be alleviated. Sometimes the sneezing is very severe. I have sneezed thirty times consecutively, and several hundred times a day. The sense of overfulness of head, with throbbing of temples, after a sneezing fit, is very distressing. When the attack is most severe, I get a tight cough, and expectorate a little mucus full of small grey pollen-like specks, which I have thought to be the mischievous grass-seeds. During the attack, I feel restless and uneasy; I have the 'fidgets' distressingly, especially if the room is close; any worry or annoyance is intolerable. The skin is hot and dry; the pulse weak. If I only see my 'coldified' swelled face in the looking-glass, or even think vividly of the illness, all the symptoms come on at once; and $I$ have heard of a sensitive Irish lady who, on seeing a picture of a harvest-field, was seized with strong symptoms of hay-fever. The severity of the attack is a good deal dependent on my state of health. Iron, arsenic, strychnine, have no effect; nor has belladonna or hydrocyanic acid. Gauze veils have proved the most effectual preventive. The eyes are comforted by zinc ointment, or by bathing with rose-water; and the irritable skin of the face, by oatmeal-water or milk. Gargling with cold water, sucking ice or iced milk, allays the painful irritation at the back of the throat. Cigarette-smoking gives temporary relief. The grass at Clevedon is to me especially irritating. I find that the attacks come on at different times in different localities. In the South of England, or near London, it begins in the last week of May or first of June ; in Switzerland, soon after the middle of May; but in Yorkshire, where I usually reside, I always look for it between the Ioth and 2oth of June, and no mistake."

CASE II. - The second case of which I give a few details is one in which the general and bronchitic symptoms were the most marked result of the irritant. The patient, an elderly country clergyman, writes : "I cannot recollect when the first symptoms appeared-I think, when I was about twenty, and lived near a trout-stream; and, being fond of fishing, was often on its banks. I recollect that violent sneezings annoyed me; and, on my return home, the frequent remark was made, 'What a cold you have!' Many years passed before the affection assumed the particular characters of hay-fever, and the attacks became periodical. They then came on as regularly as the hay-season returned, directly after being subjected to its influence. To show that this was not the effect of nervous apprehension, I may mention that I remember instances, and one in particular, in which the affection suddenly came on at a time when the source of the evil was unknown; and my vicinity to a hay-field was not ascertained till some time afterwards. I was at the seaside, and much puzzled to account for the attack, but at length discovered a small hay-field behind the house. From my father I inherited a tendency to spasmodic asthma; and so sensitive am I to cold, that a slight draught of air, even turning the leaves of a book suddenly and rapidly under my nose, would be sure to bring on a fit of sneezing. The pollen of the sweet vernal grass is the poison whence all my miseries spring ; and I think, too, some other grasses, when in flower have a like effect. The smell of roses and violets has never affected me, but that of the white clematis and evergreen honeysuckles so much that I have been obliged to remove them from my grounds. Dry hay does not always affect me ; but on one occasion, in the depth of winter, I unpacked some furniture bound up in hay, and had, in consequence, an attack of hay-asthma lasting two days. Sunlight on a white road, or dust of any kind, affects the eyes, nose, mouth, and palate, distressingly. My early attacks were characterised by sneezing, with defluxion from the nose and eyes; the membrane lining the lower part of the forehead, and the eyes, being most affected. But, as time advanced, this membrane became less sensitive, and that which lines the bronchial tubes is affected instead. The attacks assume more the characters of asthma, being worse after dinner and at night. I have had severe bronchial attacks following exposure to hay; but the last two years I have been almost free, and begin to flatter myself that I am growing out of my old complaint. Certainly it has not been aggravated by increase of years, as might have been expected. The late Governor of Bengal, who for twenty years had suffered from hay-fever in England, was free from it till his return from India. He mentioned the case of a friend who was never free except when at sea. George the Fourth suffered from hay-fever; and I have been told by a doctor, for my consolation, that he never knew any one below the degree of a gentleman, to be a sufferer from this complaint. I happen to know a young washerwoman who is a sufferer; and she has gentle blood in her veins, being a descendant of a bishop of the diocese. It is rare to find the haymakers complain, though I have met with two or three slight cases among them. I have never found any remedies effectual, though I have tried many. Iron, arsenic, quinine, iodine, bromides, prussic acid, ether, chloroform, strychnia, opium, belladonna-these are not a tithe of the drugs tried. The greatest relief obtained has been gained under a homœopathic doctor. It was curious that his remedies did no good at a distance; but, when I was under his eye, I gained immediate relief. This puzzled me for a long time, but I think I have now found the reason. This doctor lives at the seaside, at a place remarkably free from grass, and the specially noxious grasses are apparently altogether absent. I have found that I get well when in his neighbourhood, when I do not consult him or take his tinctures. In parts of Gloucestershire and Somersetshire, the grass seems to me peculiarly noxious."

CASE III. - "My first attack came on in a hay-field, when about six years old. I was brought home with supposed influenza; but it was not till I was eighteen that the annually recurring cold and asthmatic breathing was attributed to hay. It always commenced when grass was in flower, varying with the lateness of the season. The cause is unmistakably the pollen of one kind of grass (the anthoxanthum); but wheat seems sometimes to cause it. Dry hay has no effect; I could sleep on a truss of it. Haymaking time is the worst time, as the pollen is then shaken about; but sunrise, the coldest hour of the twenty-four, is the worst time. Warm weather relieves me. A cold cloudy day, with ungenial wind, is most trying. Good drenching rains seem to lay the demon low, and greatly relieve my misery. In 1832 and 1844 , the rains saved me from an attack, and I had none this year. My malady begins with itching, smarting, and irritation in the corner of the eye. The lids become so hot and swollen, that I cannot close them, or, if I do, they stick together. It passes to the nose and palate, which feel as if sprinkled with Cayenne pepper. The whole region above and behind the palate and back of the nose feels as though mashed up together; it is so swollen and undefined. And between the brain and its bone-box is a sensation like that one feels after a long run, when one's shirt, wet with perspiration, clings to the skin. My taste and smell are altogether lost. I sometimes sneeze a hundred times a day ; and, when out in the sunshine, I have sneezed so frantically as to lose my hat, and have hardly possible time to find it again between the paroxysms. I would do anything to stave off the first morning paroxysm. When I feel it coming, I seize my pocket-handkerchief and continuously blow my nose, breathing through the mouth; and sometimes I can only sleep when turned on my side with the handkerchief stuffed up my nostrils. All these symptoms, however, are pastime, in comparison with the asthma. When the chest is set fast with spasm, I struggle for breath, clutch convulsively at the back of the bed or arm of the chair, and can gain no rest save on my hands and knees, or with my head on the table. A dreadful sense of suffocation comes on, with a hard frequent cough. My face and lips are of a deep purple ; I gasp for breath, till at length I sink down exhausted and half-insensible. If roused by stimulants, I recover only to undergo a renewal of suffering. These attacks come on at night, and subside as morning approaches. Nitre-papers give some relief to the asthmatic spasm, but not till the air of the room is choking from the concentrated fumes. Smoking Espic's cigarettes, made of stramonium and Latakia tobacco, gives some relief; so does stramonium alone, or tobacco. But this last is useless, unless pushed to collapse. As the pulse fails, the face blanches, and the cold sweat stands on my forehead, miserable as is the sensation of collapse, it is Paradise to the agonies of suffocation. Happily, the disease diminishes as I get older-partly, doubtless, from greater caution and improved management; chiefly from avoiding the cause, and resorting to London or the seaside before the hay ripens. London is now so large that, when in the centre of the city, one is far from a hayfield. Thirty or forty years ago, I have, when close to the Bank, frequently smelt the hay in the fields at Islington. The sea-air relieves wonderfully, if the wind is off sea. I have started for Brighton suffering so frightfully that everybody in the coach believed I must have died, and so did I; yet within twenty-four hours I was well, save from remaining weakness." 
A form of severe catarrh is occasionally met with, frequently recurring, but lasting only two or three hours. It usually begins and ends with sneezing and profuse watery defluxion from the eyes and nose. In some cases, an asthmatic element is superadded, and dyspnoea occurs; but, in the uncomplicated form, the malady is nothing more than transient nasal catarrh. The usual time of access is the early morning. It commences on rising, and ceases soon after breakfast. It occurs in summer only, but does not appear to be dependent, like hay-fever, on any definite irritant in the air. Though in no way dangerous, it is often extremely inconvenient. A gentleman, who once consulted me on account of this malady, had travelled all over the Continent, and remained some months at sea, yachting in the Mediterranean, and had several times changed his residence from low to high ground, and from sheltered to bleak situatious, in the hope of escaping from his enemy. Several physicians, whom he had consulted, treated the matter very lightly, regarding it as ordinary catarrh; yet every summer it attacked him, and recurred nearly every morning, and sometimes in the afternoon, obliging him to leave the table or the society of those with whom he might be. Airy rooms and a cold bath act beneficially; and sal ammoniac has proved valuable. Very small doses of opium or ether, repeated several times in the hour, effectually control the affection.

Asthma is, as we all know, a wonderfully variable malady. One sufferer finds smoke and town-air the cause of a paroxysm, while another finds in it the cure. To some, the air of brick-fields is most irritating ; to others, it is as soothing balm. The form of asthma developed by hay or grass-seed is described by Dr. Salter as a " mild form of asthma"; but two instances that have come under my observation have been among the most severe. Indeed, it is difficult to exaggerate the horrors of the paroxysm. Certainly tobacco, if used early in the attack, or as a preventive, is of real value, though less, it has seemed to me, in this than in other forms of asthma. At the commencement of the paroxysm, a slight thing will determine its advance or retreat; but, when fully established, tobacco must be pushed to collapse before it relieves. Slade's stramonium cigarettes, or the compound of stramonium with Latakia tobacco, known by the name of Espic's " Fumigateur Pectoral", seems often to give relief, without producing the dreadful nausea that tobacco by itself does to the uninitiated; while to the initiated, or those accustomed to smoke freely, it may not be possible to produce nausea from smoking and even swallowing the smoke; and it is this that makes tobacco so useless a remedy to the majority of asthmatic men.

For the cure of this troublesome complaint, patients have subjected themselves to all manner of remedies. Strange theories as to the diathetic state which gives rise, or is supposed to give rise, to hayfever, have led to equally strange methods of cure. The skin, the nervous system, the stomach, have been in their turn attacked; but the conclusion at which we arrive, from the study of all these methods, is, that we cannot treat hay-fever en masse. We must treat each case individually, according to its cause and character. It is clearly im. possible to keep every one between the ages of five and forty confined to the house (haus-arrest) for two months in every year. We cannot make everybody a sailor who shows symptoms of the complaint, or even ensure all sailors being far out at sea for the dangerous time. People in England had better go to the north of Scotland while hay is made in England, and return before hay-time in Scotland comes; or go to the centre of a large city, or to the seaside. Yet there are many who cannot do this; and, for such, general and local measures, to which allusion has been made (and there are many others which naturally sug. gest themselves as meeting the plain indications present in each case), may be relied upon to mitigate the evil, and in a certain proportion of cases to effect a cure. The various attempts that have been made to remove by specifics the abnormal sensitiveness which leads to the development of disease have failed to maintain the reputation which has been promised by their promoters. The foregoing cases recorded serve to point to this conclusion, while they indicate in an unmistakable way that it is the grass which causes the malady, and not, as has been so frequently maintained, the more general causes of catarrh.

\section{INCONTINENCE AS A SYMPTOM OF RETENTION.} By JONATHAN HUTCHINSON, F.R.C.S., Surgeon to the London Hospital, etc.

INCONTINENCE of urine is every now and then the first symptom of retention, and occurs without the patient having been conscious of any distension. I have recorded in vol. iv of London Hospital Reports a remarkable instance in which this occurred from enlarged prostate, and was misunderstood both by the patient and his advisers; and another almost parallel one has just been under my care. It is, however, I think, decidedly rare for this symptom to occur in connexion with organic stricture. Now and then it occurs after extensive damage to the perinæum, with rupture of the urethra and cicatricial stricture.

A boy aged 12, whom I attended a year ago with Mr. Horton of Stepney, on account of ruptured urethra, for which we had to make free incisions, now suffers from an impassable stricture and constant incontinence of urine. $\mathrm{He}$ is obliged to wear an apparatus. Although I have failed, after most patient trials, in my endeavours to get an instrument through the stricture, yet he has no great difficulty in emptying the bladder ; and incontinence is his only trouble.

A young lady aged 16 , whom I saw not long ago with $\mathrm{Mr}$. Mundie of Dalston, had had during several years occasional incontinence of fæces, in consequence solely of distension of the rectum by an enormous hardened mass.

In March 1869, a solicitor consulted me respecting one of his clerks, whom he suspected of malingering. The youmg man sometimes stayed away from the office on account of ill-health, and had asserted, in explanation, that he suffered from great difficulty in passing urine, and also from incontinence. These two conditions seemed to his employer to be incompatible. On the following day I examined the supposed idler, and found that he had a tight stricture in the bulbous urethra, which I could not pass. As there could be no doubt that his symptoms were real and in relation with the stricture, and as they were somewhat unusual, it seems worth while to state them in detail. Four years previously he had suffered from gonorrhœe, which was only cured after several months' treatment. After this he had no gleet whatever, and a year later he married. During the last year he had experienced great and increasing difficulty in micturition. The stream had become small and twisted ; the act was attended by much forcing pain in the abdomen; the lower part of his abdomen was, he said, always uncomfortable, and he had much aching in the back. Sometimes he felt so nervous and weak that it was impossible for him to go to business. During the last two months he had had several attacks of incontinence. These had occurred sometimes during sleep and sometimes whilst walking. His bladder was full at the time he came to me ; and after my unsuccessful attempt with catheters, he immediately voided two pints in a much larger stream than he had been accustomed to for months. My interpretation of his symptoms was that his bladder habitually retained a considerable quantity, thus causing him discomfort, and perhaps having already induced renal mischief. It is easy to see how insidiously serious disease might in this way be brought about. In one of the cases alluded to above, the patient had fatal disorganisation of the kidneys, induced before any obstruction in the urethra was suspected. So misleading is the symptom of incontinence to the patient himself, who never dreams that whilst his urine escapes freely there can be any accumulation, that it becomes of the greatest importance for medical men to be on the alert as regards it.

\section{A SUGGESTION FOR THE PREVENTION OF INFECTION.}

By JAMES STARTIN, F.R.C.S., Senior Surgeon to the Hospital for Diseases of the Skin, Blackfriars.

THE rapid increase and extension of small-pox, scarlet fever, and other infectious diseases at the present time, not only in those localities which may be designated their habitual haunts, but also within the wards of general hospitals, and through the agency of public vehicles, laundries, etc., induces me to offer a suggestion, which, during twenty-five years, $I$ have been in the habit of recommending for arresting contagion in diseases of the skin. According to my knowledge, the proposition has not hitherto been employed against fevers and other sources of infection or contagion, although I am aware that it has been used in the arts for sweetening, deodorising, or disinfecting wine-casks, dairy-utensils, etc. The suggestion consists in the simple expedient of fumigating beds, clothing, closets, carriages, etc., with sulphurous acid gas, according to the following "ready method". In the case of disinfecting beds and bedding, five to fifteen minutes before the patient enters the bed, or during his removal whilst it is made, a copper warming-pan, containing a few live embers, on which a teaspoonful or two of flowers of sulphur have been thrown, is to be introduced between the sheets, and passed to and fro until the combustion of the sulphur is completed, when the pan is to be withdrawn; and, after the lapse of a few minutes, the patient may enter the bed, when, should the fumes still prove too stimulating for his respiratory organs, 